\title{
Strategies to Eliminate Mother-to-Child Transmission of HIV in Addis Ababa, Ethiopia (Qualitative Study)
}

This article was published in the following Dove Press journal: HIVIAIDS - Research and Palliative Care

\author{
Girum Sebsibie Teshome' \\ Lebitsi Maud Modiba (iD) ${ }^{2}$ \\ 'School of Nursing and Midwifery, \\ College of Health Science, Addis Ababa \\ University, Addis Ababa, Ethiopia; \\ ${ }^{2}$ Department of Health Studies, \\ University of South Africa, Pretoria, \\ South Africa
}

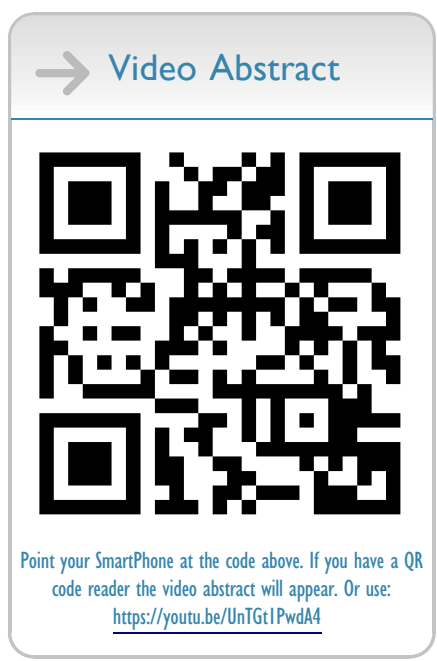

Correspondence: Girum Sebsibie Teshome

School of Nursing and Midwifery, College of Health Science, Addis Ababa

University, Ethiopia

Email girumseb@gail.com

Lebitsi Maud Modiba

Department of Health Studies, University of South Africa, South Africa

Email modiblm@unisa.ac.za
Objective: Globally, nearly 38 million people are living with HIV, and 1.8 million are children. Each day approximately 5600 people acquire HIV. Since the emerging of HIV, 78 million people have been infected and close to 39 million have died. In developing countries, from all new HIV infections, half are because of mother-to-child transmission (MTCT). The aim of this study is to evaluate the effect of option $\mathrm{B}+$ prevention of mother-to-child HIV transmission (PMTCT) and to develop strategies that contribute to eliminate MTCT in Addis Ababa, Ethiopia.

Methods: The study was conducted in three hospitals of Addis Ababa, Ethiopia, with a qualitative approach. Sixteen (16) in-depth interviews of HIV-positive mothers who had PMTCT follow-up and six focus group discussions with health professionals who work at a PMTCT unit were conducted. To analyse the data ATLAS.ti version 7 was used.

Results: According to the findings of this study mother-to-child HIV transmission was associated with lack of HIV-discordant couples counselling guideline, lack of HIV disclosure strategy and counselling guidelines, unavailability of special PMTCT counselling guideline for HIV-positive commercial sex worker mothers and lack of HIV-free human breast milk (banked human breast milk) for PMTCT. Based on the study findings, a strategy that contributes to eliminate MTCT was developed.

Conclusion: Based on the research finding, the following four strategies were developed. Strategy 1: establish and use banked human breast milk for elimination of MTCT; Strategy 2: incorporate obligatory policy for discordant couple testing, counselling and disclosure with option B+ PMTCT; Strategy 3: develop disclosure policy and counselling guideline for PMTCT; and Strategy 4: formulate special PMTCT guideline for HIV-positive commercial sex worker mothers.

Keywords: strategies, elimination of mother-to-child HIV transmission, HIV testing and counselling, prevention of mother-to-child transmission, disclosure, breast milk bank

\section{Introduction}

\section{Global Burden of HIV}

According to 2019 UNAIDS reports, 38 million people are living with HIV: 36.2 million adults and 1.8 million children under 14 years old. Only 81\% knew their HIV status, and 25.4 million were accessing antiretroviral therapy (53\% of children aged 0-14 years). About 85\% pregnant women living with HIV had access to antiretroviral medicines. Half of all HIV-positive people worldwide are women. This becomes more than half (59\%) in sub-Saharan Africa (SSA). Two-thirds 
(70\%) of adults and nearly $88 \%$ of children infected with HIV live in sub-Saharan Africa (SSA), and more than three-fourths (76\%) of AIDS deaths occurred in this region. Elimination of mother-to-child HIV transmission (MTCT) has been identified as a global public health priority in the context of the rights of a child to be born free of HIV. ${ }^{1}$

\section{HIV in Ethiopia}

According to a UNAIDS and UNICEF report, in Ethiopia, nearly 718,000 people are living with HIV/AIDS, and some 20,000 people die annually. The estimated number of orphaned children due to AIDS was more than100,000 in 2018. ${ }^{1}$ Studies show that the MTCT rate in Ethiopia by the age of 2 years is $15 \% .^{2}$ This is very high when compared to the government of Ethiopia MTCT elimination plan (provide option $\mathrm{B}+$ to $95 \%$ of HIV-positive pregnant women and having the vision of eliminating MTCT and wishing to see HIV-free child survival by 2020). In Addis Ababa, the capital city of Ethiopia, by 2016, the total number of HIV-infected children aged less than 14 years was 6990 , with an annual new infection number of 150 and 162 deaths. ${ }^{3}$ Childhood HIV morbidity and mortality can be reduced by implementing early infant diagnosis and starting ART treatment. In countries that do not practise this, the disease progression is rapid and death secondary to HIV/AIDS is high: approximately half of children HIV-infected during pregnancy or delivery die within one year. ${ }^{4}$

\section{Mother-to-Child Transmission of HIV (MTCT)}

In developing countries, from all new HIV infections, half are because of mother-to-child transmission (MTCT). More than $95 \%$ of HIV infections in children are acquired by mother-to-child HIV transmission (MTCT). Literatures indicate that breastfeeding accounts for half of all MTCT. Antiretroviral medications are highly effective for preventing MTCT of HIV (PMTCT). However, in 2018, over 240,000 children worldwide were newly infected with HIV, the majority in SSA. ${ }^{1}$ The transmission of HIV can occur from the mother to her child during perinatal period (pregnancy, delivery and breastfeeding). Without PMTCT, the chance of MTCT is $15-25 \%$ in developed countries and $25-35 \%$ in developing countries. The chance of mother-to-child HIV transmission was: during pregnancy $5-10 \%$, during labour and delivery $10-15 \%$, during breastfeeding 5-20\%, overall without breastfeeding $15-$ $25 \%$, overall with breastfeeding to six months $20-35 \%$ and overall with breastfeeding to $18-24$ months $30-45 \%{ }^{5}$

There are some clearly known maternal factors which increase the possibility of MTCT. These risks are high maternal viral load, new maternal HIV infection, decreased maternal CD4 count, maternal AIDS stage III and IV, placental infections during pregnancy and labour. Option $\mathrm{B}+$ prevention of mother-to-child HIV transmission is treating all HIV-positive pregnant and lactating mothers with lifelong ART irrespective of their CD4 count. Research indicates that the first six to eight weeks of postnatal duration had high risk of HIV transmission. But the challenge was that transmission during colostrum feeding or transmission during mature milk feeding was not identified. ${ }^{6}$

\section{Option B+ PMTCT}

In 2013, the World Health Organization (WHO) launched option B+ PMTCT on the use of antiretrovirals for treatment and prevention of MTCT. All HIV-infected women must be put on triple ART, and this will continue for life. This is option B+ PMTCT. This treatment is given daily with a combination of TDF/3TC/EFV (tenofovir disoproxil fumarate, lamivudine, efavirenz). The child must receive NVP-prophylaxis for six weeks. ${ }^{7,8}$ Option $\mathrm{B}+$ PMTCT can reduce MTCT to less than 5\% among infants who are breastfeeding and to less than $2 \%$ for infants who did not breastfeed ${ }^{9}$. In December 2013, Ethiopia started to use this option B+ PMTCT throughout the country. Option $\mathrm{B}+$ PMTCT was considered as a strategy to eliminate MTCT. Elimination of MTCT (EMTCT) is defined as reduction of new paediatric HIV infections by $90 \%$ and reduction of mother-to-child HIV transmission rate to less than $2 \%{ }^{10}$

Option B+ PMTCT service is given free of charge in health care facilities of Ethiopia since December 2013. Option B+ PMTCT recommends lifelong ART. This will disclose maternal HIV status and result in psychological side effects (discrimination). Option B+ PMTCT has several advantages over the previous options A or B. Some of these advantages are: there is no need to stop ART after the birth of the baby or after the cessation of breastfeeding and risk of MTCT has decreased. With extended protection in future pregnancies for MTCT from the very early stage, sero-discordant couples or partners will benefit by the intervention. The client will benefit in two ways. First, regular stopping and starting in cases of high fertility with 
consequent development of more chances of drug resistance can be avoided. Secondly, the client will benefit by early start of treatment and a simple and straight message to the community, that once ART is started, it should not be stopped. ${ }^{11,12}$

Option B+ PMTCT also recommended for all HIVexposed infants to take nevirapine prophylaxis for 6 weeks. According to this option, exclusive breastfeeding is advised, but breast milk substitute is possible based on the maternal preference. ${ }^{13}$ The option B+ PMTCT programme is family centred and acts as an entry point for paediatrics HIV care, ARV treatment, protection and care of orphans and vulnerable children. ${ }^{13,14}$ There are four global strategies or prongs of eliminating mother-to-child HIV transmission. These components (prongs) are: Primary prevention of HIV infection among women of childbearing age; Prevention of unwanted pregnancy among HIV-positive women; Appropriate use of option B+ PMTCT; and Providing appropriate treatment, care and support to mothers living with HIV and their children and families. ${ }^{15}$

\section{Study Rationale/Justification}

In order to achieve the global plan of elimination of MTCT, the coverage of the option B+ PMTCT service should address all the urban and rural parts of the country so that pregnant women can get HIV testing and if positive can start lifelong ART. The global plan of eliminating MTCT recommends having regular HIV testing for all pregnant and lactating mothers at the first possible opportunity. The option $\mathrm{B}+$ PMTCT guideline had a limitation on disclosure of HIV status and counselling for HIV sero-discordant couples.

The existing option B+ PMTCT programme lacks adequate coverage for pregnant female sex workers. PMTCT service for female sex workers like a tracing, counselling and retention system should be strict and separated from others. Despite efforts on PMTCT and coverage improvement in Ethiopia, there is still a gap in: identifying determinants of MTCT, the effect of option B+ PMTCT, timing of MTCT, HIV status of exposed infants, male involvement on PMTCT and age of infant at diagnosis.

Option B+ PMTCT was launched to reduce MTCT to less than $2 \%$. However, EFMOH's statistics shows that MTCT reaches up to $15 \%$, which is too far from the plan of $\leq 50$ new paediatric infections per 100,000 live births and MTCT $<5 \%$ in breastfeeding populations or $<2 \%$ in non-breastfeeding populations. ${ }^{16}$ Option B+ PMTCT is an opportunity, not yet a solution. ${ }^{17}$ Even though strategic interventions to eliminate MTCT of HIV exist across the world, it still did not totally eliminate MTCT.

In Ethiopia factors affecting MTCT, like maternal retention in option B+ PMTCT follow-up, HIV disclosure, knowledge about the importance of option $\mathrm{B}+$ for maternal-child health and maternal and health professionals' perception about PMTCT, are not well studied.

Therefore continuous evaluation of the effect of existing strategy (option B+ PMTCT) is mandatory to identify the gap and to develop alternative strategies that eliminate MTCT.

The findings of this study will be used to develop strategies that contribute towards the elimination of MTCT and improving the mothers' and babies' health status. It would also ensure HIV-free children and MTCT no longer being a public health problem in Addis Ababa, Ethiopia. The result of this study will have contribution for educational purposes by improving health professionals' skill and knowledge on PMTCT. The findings and recommendations of this study will be a benchmark for further researchers.

\section{Methods and Materials} Study Design, Area and Period

The study was conducted in Addis Ababa, the capital city of Ethiopia, established in 1887 by Emperor Menelik II. Addis Ababa has a total population of 7.171 million people in 2019. The study was conducted in three governmental hospitals of Addis Ababa. The hospitals were selected by using simple random sampling method. HIV-positive mothers who had follow-up in the study hospital and health professionals who give PMTCT service were the study population. Phenomenological study design for in-depth interview of HIV-positive mothers and ethnographic study design for FGD of health professionals were used. This study was conducted from February 2018 to April 2018.

\section{Sample and Sampling Methods}

The mothers were traced by referring to a PMTCT followup chart, and 16 in-depth interviews were conducted. Six FGD of health professionals who delivered PMTCT services in the study hospital were conducted. The final numbers of FGDs were determined by saturation of data.

\section{Data Collection Methods and Procedures}

Six FGD with health professionals who delivered PMTCT service in the study hospital and 16 in-depth interviews with HIV-positive mothers were conducted. Mothers were asked for consent when they come for ART follow-up and 
interviewed in a private room. The researcher used a tape recorder and took field notes while conducting FGD and indepth interviews. The number of health professional participants in each FGD ranges from 6 to 8. In order to maintain anonymity the participant individuals were assigned as $\mathrm{p} 1$, p2, p3 etc. The final number of FGDs and in-depth interviews were determined by saturation of data.

\section{Data Management and Analysis}

To analyse the data ATLAS.ti version 7 software was used, and this facilitates the thematic analysis. The qualitative data analysis was performed according to the following steps:

Step 1: Organise and prepare the data for analysis. This step includes transcription and translation of the interview material/data, scanning of the material if necessary, writing field notes, classifying the visual material, sorting and arranging the data into different file. Step 2: Read and check the collected data whether it gives meaningful information or not. Check the main ideas that the participants talk about, the tone of ideas, the impression of the audience, credibility and use of the information. Step 3: Code all of the data. This may be text, figures or pictures collected during the field. Usually it was labelled or categorised by the actual or participants' own language (in vivo term). Step 4: Prepare themes and subthemes for further analysis. Detailed description of the information about people, places or events in a study or a collected dataset is made in this step. Step 5: Themes and sub-themes described in step four were put as a qualitative narrative. The usual method of qualitative narrative is passaging to take the findings of the analysis. This may be explained in an orderly fashion of events and detail discussion about categorised themes and sub-themes. Step 6: A final step in qualitative data analysis is making an interpretation of the findings or results. This involves setting out the specific lessons learned and getting to the core of the idea. ${ }^{18}$

\section{Trustworthiness of the Study}

The researcher strictly uses the following to maintain the study's trustworthiness: Credibility - The researcher would spend adequate time for the study. The researcher should be available during data collection so that appropriate supervision and responses to any claim from data collectors or study participants can be made. Dependability - The researcher would provide detailed description of the process used, like the process and reason for sample requirement, procedure, step and length of data collection, data analysis and presentation. Audio-recorded interviews and field notes are kept in a safe place. Conformability - The researcher kept field notes and audiotape recordings in a safe place even after the publication of the research for a period of two years. Transferability - Conducting in-depth analysis of interview transcripts, documents and observational notes. The result of this study can be utilised in other areas of Ethiopia. Triangulation - Adding validity to the study by using different data sources and methods. If the study is established based on integrating different sources of data and from different participants, then this process can increase the validity of the research. ${ }^{18}$ Rigour - Rigour and truth are always the backbone of qualitative study. Rigour has also been used to express attributes related to the qualitative research process. The researcher will have a witness for the strength of the research design and the appropriateness of the method to answer the questions if rigour is maintained.

\section{Operational Definitions}

Mother-to-child transmission (MTCT): According to this research, Mother-to-child transmission refers to the transmission of the HIV virus from a mother to her child. Transmission can occur during pregnancy, labour and delivery, or through breastfeeding. ${ }^{14}$ Option $\mathrm{B}+$ : Providing lifelong triple ART for all pregnant and breastfeeding women living with HIV. ${ }^{14}$ Strategy: A set of programmes or policies implemented primarily to have an impact on a specific illness or disease. Eliminate MTCT: According to this study, eliminate MTCT means having zero mother-to-child HIV transmission during perinatal period. Replacement feeding: According to this study, it is the act of, in the context of HIV/AIDS, feeding a child who is not receiving any breast milk with a diet that provides all the nutrients the child needs.

\section{Results}

The findings of this study are presented according to the following research questions: How is option B+ PMTCT perceived by health professionals at governmental hospitals of Addis Ababa, Ethiopia? What is the perception of mothers about the option B+ PMTCT of HIV at governmental hospitals of Addis Ababa, Ethiopia? And what interventions can be used to eliminate mother-to-child HIV transmission at governmental hospitals of Addis Ababa, Ethiopia?

\section{Socio-Demographic Characteristics of Health Professionals Who Participated in Focus Group Discussion (FGD)}

Of all the health professionals who participated in the FGD, only four were midwives and the other 32 were nurses. All 
health professionals were BSc degree holders, and all of them were trained on PMTCT. Regarding their work experience in PMTCT unit, only ten health professionals had experience of less than five years, and the remaining 26 health professional had experience of five years and above.

\section{Socio-Demographic Characteristics of Mothers Who Participated in In-Depth Interviews}

The characteristics of the 16 mothers who participated in in-depth interview is displayed in Table 1.

\section{Thematic Analysis of Focus Group Discussion (FGD) and In-Depth Interviews (IDI)}

The thematic analysis of this study had three main themes and ten sub-themes. These main themes and sub-themes are selected and categorised based on the ideas that most of the participants agreed with or raised, and they include: 1) Effect of option B+ PMTCT: Benefit of option B+ PMTCT (for the mother, for the infant); Side effects of option B+ PMTCT (for the mother, for the infant). 2) Individual/family/community factors about option B+ PMTCT: HIV sero-discordant couple; disclosure of HIV status for sexual partner; community perception about option B+ PMTCT; PMTCT for commercial sex worker mothers; and availability of HIV-free human breast milk for PMTCT. 3) Strategies to eliminate MTCT: develop HIV discordant couples' PMTCT counselling and disclosure guidelines; develop special counselling PMTCT guidelines for commercial sex worker HIV-positive mothers; and use of HIV-free human breast milk (human breast milk bank) for PMTCT. The above main themes and sub-themes are summarised with their frequency in focus group discussions and individual in-depth interviews (Table 2).

\section{Effect of Option B+ Prevention of Mother-to-Child HIV Transmission}

The FGD participants compare the previous option A and option $\mathrm{B}$ with option $\mathrm{B}+$, and most of participants agree that option $\mathrm{B}+$ is better. The study participants explain this issue as:

When I compare from the previous options (option A and option B), the current option (option $\mathrm{B}+$ ) is better; there is no interruption of ART like the previous options, the follow-up is better in this option because it had 18 months of follow-up. (FGD-1)

This idea is also supported by in-depth interviews of HIVpositive mothers as follows:

The current option of PMTCT is better. I can give witness for this. My last child is born free from the virus as I took the

Table I Socio-Demographic Characteristics of Mothers Who Participated in In-Depth Interview on Strategies to Eliminate MTCT of HIV in Addis Ababa Governmental Hospitals, Ethiopia, 2018

\begin{tabular}{|c|c|c|c|c|c|c|c|}
\hline IDI & $\begin{array}{l}\text { Mothers' } \\
\text { Age }\end{array}$ & $\begin{array}{l}\text { Marital } \\
\text { Status }\end{array}$ & Religion & Education Level & Occupation & $\begin{array}{l}\text { Husband's HIV } \\
\text { Status }\end{array}$ & $\begin{array}{l}\text { Infants' HIV } \\
\text { Status } \\
\text { by DBS }\end{array}$ \\
\hline MI & 30 years & Married & Orthodox & Grade 10 & Private & Positive & Negative \\
\hline M2 & 34 years & Married & Orthodox & Grade 8 & House wife & Positive & Negative \\
\hline M3 & 37 years & Married & Protestant & Grade 12 & Private & Positive & Negative \\
\hline M4 & 27 years & Married & Orthodox & Grade 4 & House wife & Negative & Negative \\
\hline M5 & 25 years & Married & Orthodox & Grade 10 & Government employed & Positive & Negative \\
\hline M6 & 25 years & Married & Muslim & Illiterate & House wife & Unknown & Negative \\
\hline M7 & 28 years & Married & Protestant & Grade 10 & Private & Positive & Negative \\
\hline M8 & 31 years & Separated & Orthodox & Diploma & Government employed & Positive & Negative \\
\hline M9 & 37 years & Married & Orthodox & Grade 7 & House wife & Positive & Negative \\
\hline MIO & 32 years & Married & Orthodox & Diploma & Government employed & Positive & Negative \\
\hline MII & 32 years & Married & Muslim & Grade $10+2$ certified & Government employed & Negative & Negative \\
\hline MI2 & 24 years & Married & Orthodox & Diploma & Government employed & Positive & Negative \\
\hline MI3 & 31 years & Married & Orthodox & Degree & Government employed & Positive & Negative \\
\hline MI4 & 31 years & Married & Protestant & Illiterate & House wife & Negative & Negative \\
\hline MI5 & 32 years & Married & Orthodox & Degree & Government employed & Positive & Negative \\
\hline MI6 & 37 years & Married & Orthodox & Illiterate & House wife & Positive & Negative \\
\hline
\end{tabular}

Abbreviations: M, mother; DBS, dry blood spot test; IDI, individual in-depth interview. 
Table 2 Thematic Analysis for FGDs and In-Depth Interviews (IDI) on Strategies to Eliminate MTCT of HIV in Addis Ababa Governmental Hospitals, Ethiopia, 2018

\begin{tabular}{|c|c|c|c|}
\hline Main Theme & Sub-Themes & $\begin{array}{l}\text { IDI/Page No. } \\
\text { (I Up to I6) }\end{array}$ & $\begin{array}{l}\text { FGD/Page No. } \\
\text { (FGD I-6) }\end{array}$ \\
\hline \multirow[t]{2}{*}{$\begin{array}{l}\text { Effect of option B } \\
+ \text { PMTCT }\end{array}$} & $\begin{array}{l}\text { Benefits of option B+ PMTCT } \\
\text { For the mother } \\
\text { For the infant }\end{array}$ & $\begin{array}{l}\text { IDI-2, P2; IDI-II, P7; IDI-5, PI; } \\
\text { IDI-I3, PI }\end{array}$ & FGD-I, p3-5; FGD-3, p5-8 \\
\hline & $\begin{array}{l}\text { Side effect of option B+ PMTCT } \\
\text { For the mother } \\
\text { For the infant }\end{array}$ & IDI-I, P5; IDI-2, P4; IDI-5, P2 & FGD-I, pI3; FGD-2, pl0 \\
\hline \multirow{5}{*}{$\begin{array}{l}\text { Individual/Family/ } \\
\text { Community } \\
\text { Factor }\end{array}$} & HIV sero-discordant couple & $\begin{array}{l}\text { IDI-I, P3, IDI-2, P2; IDI-8, P2; } \\
\text { IDII4, P2; IDI-6, P2 }\end{array}$ & $\begin{array}{l}\text { FGD-I, p5; FGD-2, p4,5; } \\
\text { FGD-4, p3 }\end{array}$ \\
\hline & Disclosure of HIV status for sexual partner & $\begin{array}{l}\text { IDI-2, P2; IDI-3, P3; IDI-7, PI; } \\
\text { IDI-9, PI }\end{array}$ & $\begin{array}{l}\text { FGD-I, p8; FGD-2, p7; } \\
\text { FGD-3, p7; FGD-4, p4 }\end{array}$ \\
\hline & Community perception of option B+ PMTCT & IDI-I, P3; IDI-2, P3; IDI-3, P3 & $\begin{array}{l}\text { FGD-I, pI3; FGD-2, p6; } \\
\text { FGD-3, p7 }\end{array}$ \\
\hline & PMTCT for commercial sex worker mothers & IDI-I, P5; IDI-2, P4; IDI-5, P2 & FGD-I, pI3; FGD-2, pl0 \\
\hline & Availability of HIV-free human breast milk for PMTCT & $\begin{array}{l}\text { IDI-I, P3; IDI-5, PI; IDI-7, PI; } \\
\text { IDI-II, PI; IDI-I3, P2 }\end{array}$ & $\begin{array}{l}\text { FGD-I, p7-8; FGD-2, pl0; } \\
\text { FGD-3, p9; FGD-4, p4 }\end{array}$ \\
\hline \multirow[t]{3}{*}{$\begin{array}{l}\text { Strategies to } \\
\text { eliminate MTCT }\end{array}$} & $\begin{array}{l}\text { Develop HIV-discordant couples PMTCT counselling and } \\
\text { disclosure guideline }\end{array}$ & IDI-I, P2, IDI-2, P3; IDI-3, P2 & $\begin{array}{l}\text { FGD-I, p6; FGD-2, p5; } \\
\text { FGD-3, p5; FGD-4, p2 }\end{array}$ \\
\hline & $\begin{array}{l}\text { Develop special counselling PMTCT guideline for } \\
\text { commercial sex worker HIV-positive mothers }\end{array}$ & IDI-3, P2; IDI-8, P3; IDI-I0, PI & $\begin{array}{l}\text { FGD-I, p8; FGD-2, p8; } \\
\text { FGD-3, pI I }\end{array}$ \\
\hline & $\begin{array}{l}\text { Use of HIV-free human breast milk } \\
\text { (human breast milk bank) for PMTCT }\end{array}$ & IDI-2, P2; IDI-I, P4 & $\begin{array}{l}\text { FGD-I, p7,10; FGD-2, p8; } \\
\text { FGD-3, pII }\end{array}$ \\
\hline
\end{tabular}

Abbreviations: IDI, individual in-depth interview; FGD, focus group discussion; P, page number.

drug properly. It was after the start of current PMTCT (option $\mathrm{B}+$ ). My first child was HIV positive due to unaware of my HIV status and short follow-up duration with the previous option. The current option is also important to decrease the viral load by using condom during sexual intercourse as advised by the health care providers. (IDI-1)

One FGD participant also compares the advantage of prolonged follow-up of option $\mathrm{B}+$ and states the following:

The previous option had short follow-up duration. Then it is difficult to know whether the infant is positive or not. Option $\mathrm{B}+$ is better, it had adequate time of follow-up, I get only two infants who were positive with this option $\mathrm{B}+$ and this is because of the negligence of mothers and unwillingness. She did not take the medication properly, she did not want to disclose her HIV status for her husband and even she did not give the infant's prophylaxis. This all were a problem of negligence and disclosure. (FGD-1)

\section{Side Effect of Option B+ PMTCT}

In the previous PMTCT options, TDF was not recommended because of fear of teratogenicity. Some of the FGD participants explain that there is a problem with TDF regarding the side effect of option $\mathrm{B}+$. They said the rumour about congenital anomalies is high among mothers who take TDF, but it is not confirmed whether the problem is with TDF or another cause. The FGD participants explained this issue as:

There is no significant side effect with option B + ART drugs but it may result in different birth outcome like congenital anomalies, low birth weight, preterm etc ... But I am not sure that wither the problem occurs because of the use of ART or other problem". "We had a fear that TDF will result in congenital abnormalities if the mother take during pregnancy. This is due to previous knowledge and it may not be the actual practice. (FGD-2 ; FGD-6) 
I am BSc nurse with an experience of more than 10 years working in this PMTCT unit and option B+ had some side effects for the mother like bleeding after they start taking the medication, and this makes the mothers to have fear on the use of ART or option B+ medication. The other participants said: I had an experience that three mothers were aborted when they start option B+ ART medication and they were complaining that it is because of the medication. (FGD-3 and FGD-2)

\section{Duration of PMTCT Started and Outcome of Infants' HIV Status}

Time of MTCT is dependent on different factors. The recommended time to become pregnant is when the viral load becomes low and there is an increased CD4 count. One FGD participant of this study shared this idea and stated:

\begin{abstract}
The main risk that increases MTCT is that the mothers will have unplanned pregnancy with high viral load and low CD4 cell. Even I recommend not becoming pregnant with this condition the mother did not accept. Especially HIV serodiscordant (mothers whose husband is HIV negative) had unplanned pregnancy. This is because of a problem of disclosure. If the mother did not disclose her HIV status, it is difficult to use condom during intercourse and will face unplanned pregnancy (FGD-2 page 2 and 3). As to me having sexual intercourse without condom results in transfer of HIV from my husband to me and this will increase the chance of HIV transmission from me to my child. (IDI-1)
\end{abstract}

\section{Effect of Sero-Discordant Couple on Prevention of Mother-to-Child HIV \\ Transmission}

The term "sero-discordancy" encompasses sero-discordant and sero-concordant heterosexual couples. Sero-discordant or sero-discordance exists when one sexual partner is HIVnegative and the other is positive. Currently HIV serodiscordance results in high transmission rates of HIV and is a common problem in PMTCT units. The FGD participants explain this issue as follows:

Discordant result is the big problem I face in this PMTCT unit. We are preventing MTCT but we cannot prevent from the mother to her husband. (FGD-2)

The guideline had limitation on couple counselling and testing. The health professionals recommend having a special guideline on counselling of HIV sero-discordant couples.
The government or health office should have a special and different strategies or guideline for counselling discordant couples. With this guideline it very difficult to trace discordant couple and give appropriate counselling and treatment. (FGD-2)

\section{Disclosure of HIV Status for Sexual Partner}

Disclosure of HIV status to his/her sexual partner is known as partner notification. This will happen when an authorised individual in a health facility or health system shares a person's HIV test result with that person's partner, or partners. Some patients did not agree to disclose their HIV-positive status. This idea was explained by the HIVpositive mothers as follows.

I didn't disclose for anybody even for my manager in the workplace, when I absent from the workplace, I ask my doctor to give me a sick leave. This sick leave does not mention the diseases type (my HIV status), so they didn't know. The reason for doing this is by observing other. My friends who are positive and disclose their HIV status, they separate or discriminate from others and at that time, I fell disappointed, but in work place I respect and take full responsibility of care to protect them. In most of the time we use blade in work place and always I took the blade in the evening that I used in the place which is reserved for such purpose and they didn't get for using it. By doing so, I can prevent the transmission of HIV from me to my friends. But my family knows that I am HIV positive, my mother, brothers and sisters and also my husband family know my HIV status. My sister is a nurse and she also helps me. (IDI-8)

Reluctance to disclose HIV also has a negative effect on women's treatment outcomes and PMTCT service. This is also supported by participants of this research.

Mothers did not give the medication on time, there is always an interruption of the prophylaxis for their child and this is because of unable to disclosure and not to show the medication for the others. The medication is given secretly by the mother. No one knows except the mother. (FGD-2)

My husband and some close relatives know my HIV status. It is good to disclose for others specially for reminding of the timing to take my drug and the baby's drug. (IDI-1)

In Ethiopia traditionally, people live together, and it is difficult to practise things in secret. As a result, HIV 
prophylaxis for the infant will not be given regularly and results in transmission of HIV from his/her mother.

In our culture people are living together or in the same household, and this is difficult to live with secrete for a long period. There is a difficulty with NVP, because mothers did not want to take it, everybody knows the cover of NVP and they ask to change the cover or to cover with other paper, plastic which is not known by other family members. (FGD-5)

According to the current PMTCT guideline, only the mother can disclose her HIV status to the husband and no one can tell him except her. The health professionals suggest the following solution:

I do have one suggestion, at the first time when the mother comes to the ANC and PMTCT service she should come with her husband and must be tested together unless and otherwise we are trying to prevent MTCT but allowing to have HIV to the husband. In this case, the husband did not support her in prevention of MTCT and HIV transmission will be high. Elimination of MTCT without male involvement is difficult. (FGD-4)

\section{Use of Human Breast Milk Bank for the Prevention of MTCT}

The advantages of using exclusive breastfeeding to both babies and mothers are well proven. There is a challenge both from mothers and health professionals regarding use of donated breast milk and this is explained as:

Establishing breast milk bank and collecting human breast milk and giving for HIV exposed infants will be a good solution. This makes zero transmission during breastfeeding. But this will have challenge on the donation of breast milk and the attitude of mothers to give breast milk from breast milk bank. (FGD-2)

Breast milk bank establishment is a good idea and good solution but since it is a new for our country a lot must be done on adaptation and awareness creation. It is an impressive idea. Breast milk bank is a very good solution because we can speak that no transmission during breastfeeding. This will be important even for other infants who did not get exclusive breastfeeding. (FGD-2)

Establishing breast milk bank and will be useful to get of exclusive breastfeeding for those who are unable to breast feed. If there is a way in which a child gets HIV free breast milk it is possible that MTCT during breastfeeding will be zero or eliminated. (FGD-2)
Another FGD participant explains her idea as follows;

I think breast milk donation is possible; the question is that how much mothers will use it? But it can eliminate HIV transmission during breastfeeding. There is a trained that infants whose mother had died, they will breast feed from other individuals (mothers sister, grand-mother or someone else) but in this days because of HIV and other infectious disease which transmitted via breast milk, it should be in the form of breast milk bank and the health of the milk must be secured. Any way it is a good idea and must be work hard on it. Mother will happy when they inform that they can breastfeed their exposed infant. And they may be happy to use breast milk bank. (FGD-1)

Islamic law prohibits marriage between the donor's offspring and the recipient of donor milk. These ideas were explained in-depth by the participant mothers as follows:

It is an impressive idea. Breast milk bank is a very good solution because we can speak that no transmission during breastfeeding. This will be important even for other infants who did not get exclusive breastfeeding. But I had a question on the cost, contamination and awareness of how to get and use it. (IDI-7)

Breast milk bank establishment is a good idea and good solution but since it is a new for our country a lot must be done on adaptation and awareness creation. It is also good to consider the opinion of different religion especially Islamic followers. (FGD-2)

\section{PMTCT for Commercial Sex Worker Mothers}

The service of option B+ PMTCT is compromised by HIV-positive commercial sex workers mothers. The FGD participants of this study reflected their idea regarding this issue.

There is a problem with commercial sex workers, they will deliver at home and they come late for the purpose of vaccination, and even I recommend to start prophylaxis for her infant she will not come again, I cannot get her again because she give me false phone number. Commercial sex workers mothers come from far area because of fear of the community in their nearby health institution. As a result, it will be difficult for regular and continuous PMTCT follow-up. (FGD-2)

\section{Discussion}

The aim of this study was to evaluate the effect of option B+ PMTCT by exploring the perception of health 
professionals who work in PMTCT units and HIV-positive mothers on PMTCT follow-up about the option B+ PMTCT and to develop strategies that contribute to eliminate MTCT in Addis Ababa, Ethiopia.

\section{Effect of Option B+ Prevention of Mother-to-Child HIV Transmission Advantages of Option B+ PMTCT}

Different evidence showed that there is a significant reduction of MTCT after the introduction of option B+ PMTCT. The Ethiopian federal ministry of health had a plan to increase the coverage of option $\mathrm{B}+$ in all health institutions with a plan of reducing new HIV infection among children by $90 \%$ and reducing the MTCT rate to $<2 \%$ by 2020 . To achieve these, the following lists of interventions were planned: strengthen mother-baby follow-up and assure the service is delivered appropriately in all health institutions; monitor and evaluate the PMTCT practice to discover whether it is done according to elimination of MTCT strategic plan or not; improve the service and coverage of early infant diagnosis (EID) in all parts of the country; prevent loss to follow-up and improve the integration service with other programmes. This plan was supported by the FGD and IDI participants of this study. The FGD participants compare the previous option A and option $\mathrm{B}$ with option $\mathrm{B}+$, and most of participants agree that option $\mathrm{B}+$ is better.

Option $\mathrm{B}+$ had an advantage of long follow-up for the infant, lifelong ART for the mothers and prophylaxis for exposed infants and if positive an immediate start on ART. The three important positive aspects of option B+ PMTCT identified by mothers who had follow-up include: 1) prolonged lactation is possible with better child health by using option $\mathrm{B}+$; 2) behaviourally they feel healthier because they are on treatment; 3) reduction of stigma towards mother and child. ${ }^{10}$ Recent literature shows that option B+ PMTCT has the following advantages over the previous options. First, regular stopping and starting in cases of high fertility with consequent development of more chances of drug resistance can be avoided. Secondly, the client will benefit by early start of treatment and a simple and straight message to the community, that once ART is started it should not be stopped. ${ }^{19}$ The FGD participants also considered the advantage of prolonged follow-up of option $\mathrm{B}+$, and they agree that option $\mathrm{B}+$ is better (FGD-1).

\section{Side Effect of Option B+ PMTCT}

In the previous PMTCT options, TDF was not recommended because of fear of teratogenicity of TDF. But with the current PMTCT option (option B+), TDF is not contraindicated. Because of this previous knowledge, health professionals feared that congenital anomalies will increase in infants born from mothers who take TDF for PMTCT. Some of the participants explain that there is a problem with TDF regarding the side effect of option $\mathrm{B}+$ PMTCT. They said the rumour about congenital anomalies will increase with mothers who take TDF, but it is not confirmed whether the problem is with TDF or other causes. The FGD participants also agree with the above issue. (SeeResults section, FGD-2, FGD-6, FGD-3, and FGD-2).

\section{Duration of PMTCT Started and Outcome of Infants' HIV Status}

Time of MTCT is dependent on different factors. Some of the factors include maternal CD4+ cell counts, maternal RNA viral load and duration of breastfeeding. The probability of transmission during pregnancy is in the range 5$10 \%$, during delivery $10-15 \%$ and during lactation $5-20 \%$. Total transmission with the absence of breastfeeding is approximately $15-25 \%$. This transmission only within six month is in the range $20-35 \%$, and total transmission including breastfeeding to $18-24$ months reaches 30 45\%. ${ }^{5}$ Mother-to-child HIV transmission during pregnancy will increase if mothers become pregnant without plan and health professional recommendation. The recommended time to become pregnant is when the viral load becomes low and the CD4 count increases. FGD participants of this study shared the above fact.

\section{Effect of Sero-Discordant Couples on Prevention of Mother-to-Child HIV}

\section{Transmission}

The term "sero-discordancy" encompasses sero-discordant and sero-concordant heterosexual couples. Sero-discordant or sero-discordance exists when one sexual partner is HIV negative and the other is positive. This difference in HIV sero-status may have a risk of transmission to the negative partner. In order to prevent this HIV transmission, condom use is mandatory during sexual intercourse (married or cohabiting). ${ }^{20}$

It is recommended that sexual partners or couples get tested for HIV together. This makes the process of mutual 
disclosure easier. Advice including on reproductive health, use of family planning and prevention of STI and HIV can be easily given if a couple test is performed. Currently HIV sero-discordant couples have high rates of HIV transmission, and this is a common problem in the PMTCT unit. This is consistent with the ideas of health professionals participating in FGD (FGD-2, p5). The current Ethiopian PMTCT guideline recommend couple counselling, but it is not a must. The guideline had a limitation on couple counselling and testing. The health professionals recommend having a special guideline on counselling of HIV sero-discordant couple. The limitation of option B+ PMTCT is also raised by FGD participants (FGD-2).

\section{Disclosure of HIV Status for Sexual Partner}

Disclosure of HIV status to his/her sexual partner is known as partner notification. This will happen when an authorised individual in a health facility or health system shares a person's HIV test result with that person's partner, or partners. The positive side of disclosure of a HIV status to a sexual partner is that it may motivate the partner for VCT, reduce risky behaviours and increase acquisition of support and adherence to ART. But on the other hand, it may cause blame, discrimination, abandonment, depression, loss of economic support and disruption of family relationship. ${ }^{21}$ Therefore, some patients did not agree to disclose their HIV positive status. This notion was supported by HIV-positive mothers who participated in this study (IDI-8).

Reluctance to disclose HIV also has a negative effect on women's treatment outcomes and PMTCT service. Anticipating negative consequences, the way of disclosing and starting ART are some of the factors associated with disclosure of HIV status. ${ }^{22}$ A study done in Tanzania shows that HIV-infected persons need advice from a person that they told. In another study conducted in Ethiopia different determinant factors were identified for disclosure of HIV status, including educational level and ART use. ${ }^{23}$

In Ethiopia, traditionally, people live together and it is difficult to practise things in secret. As a result, HIV prophylaxis for the infant will not be given regularly, and this results in transmission of HIV from his/her mother. According to the current PMTCT guideline, only the mother can disclose her HIV status to the husband and no one can tell him except her. Usually, the mothers did not want to disclose, especially if she is positive and her sexual partner is HIV-negative. In this study, all HIV serodiscordant couples are HIV-positive mothers and HIVnegative fathers.

\section{Use of Human Breast Milk Bank for the Prevention of MTCT}

Exclusive breastfeeding is ideal for the best of child growth and mental development for the first 2 years of life. Breastfeeding is recommended to continue for up to two years of age, or beyond, to meet the infants' evolving nutritional needs with safe complementary foods. ${ }^{24}$ There are human breast milk banks world-wide that provide breast milk for babies who are preterm, sick and had not enough milk from their mothers. ${ }^{25}$ The idea of a human milk bank emerged and became established in 1909 in Vienna, Austria. Human milk bank was immediately disseminated to the European countries during the 20th century. Banked human milk was widely used for newborns that did not get milk from their mothers. A study done by the European Milk Banks Association in 2017 about global human milk bank distribution shows that there are 220 in Europe, 22 in India, 12 in China, 4 in Australia, 26 in USA and Canada, 6 in Cameroon, 258 in South America, 17 in Mexico, 6 in Philippines and approximately 60 human breast milk banks were found in South Africa. ${ }^{26}$

Several well organised human breast milk banks and guidelines have been established in Europe, America, Australia and Britain. Breast milk banks recruited and screened mothers who have excess milk or are willing to express for the milk bank beyond their own baby's needs. ${ }^{27}$ These countries have also set policies, guidelines and protocols for monitoring the process from breast milk donation, collection, sterilisation and prescription, as well as rights of parents and recipients. ${ }^{28}$

Even though there is fast growth of the use and expansion of breast milk bank, one study identifies a number of challenges and barriers to establishing and using a human milk bank. ${ }^{29}$ These include: High costs of the establishment and operation of breast milk bank; The mothers had fears on the safety of banked milk; Lack of awareness and support from health professionals; and Some cultural and religious beliefs and practices had resistance to the use of donated milk (for instance, milk kinship occurs after milk donation, and Islamic law prohibits marriage between the donor's offspring and the recipient of donor milk). The above challenges were raised by both mothers and health 
professionals regarding use of donated breast milk. (See the Results section, FGD-2, FGD-2, FGD-1, IDI-5, IDI-7).

Human donor milk is not exactly equal and the same as fresh mother's milk. There is a loss of some micronutrients and anti-infective factors from the banked milk during boiling/pasteurisation, and reduced through time, and variation of nutrients may occur. But this does not mean that sufficient bioactivity and the beneficial immunological properties of the milk are absent. Many studies confirm that banked milk is better than all types of formula replacement feedings. ${ }^{30}$

\section{PMTCT for Commercial Sex Worker Mothers}

Globally the prevalence of HIV is 13.5 times more common among female sex workers than the whole female population. Tracing and retaining female sex worker mothers and their infants for PMTCT service is mandatory. The perception of the community towards female sex workers is not good. Many countries did not have special service of HIV care and treatment for these vulnerable populations. The female sex workers are perceived by the community as criminal. Stigma, discrimination and violence are the challenge of female sex workers. ${ }^{31}$ Health service programmers and PMTCT planners should include HIV-vulnerable groups like female sex workers.

To achieve the goal of elimination of MTCT through proper application of the 90-90-90 strategy by 2020 , inclusion of female sex workers in PMTCT services is mandatory. ${ }^{32}$ In Ethiopia, female commercial sex workers are illegal within the community. Sexual activities as a transaction are not allowed legally, but the issue is common in most of Ethiopian towns, and this is because it is not prohibited by law. The literature indicates that the number of female sex workers in Ethiopia is increasing and most of the participants who join the sex trade are young girls. According to a study done in Ethiopia in 2014, the prevalence of HIV among female sex workers ranges from $15 \%$ to $33 \%$. This is very high when it is compared to the national HIV prevalence which is $0.9 \%$. The FGD participants of this study reflected that option B+ PMTCT is compromised by HIV-positive commercial sex worker mothers (FGD-2).

\section{Strategies to Eliminate Mother-to- Child HIV Transmission Based on the Research Findings}

After reviewing the literature, and based on these findings, a four-strategy framework was developed. The purpose of the strategies is to provide evidence-based recommendations which contribute to the elimination of mother-tochild HIV transmission in Ethiopia. This framework will guide the operationalisation of the detailed strategy. The four key strategies in the framework are explained with detailed justification as follows below (Figure 1).

\section{Strategy Towards Establishing and Use of Banked Human Breast Milk for PMTCT}

The emerging of HIV/AIDS in the early 1980s was a great challenge for the use of the breast milk bank. This is because HIV is transmitted via breast milk. But after a time it was understood that this can be prevented and screened for. The other problem with using banked breast milk was the cost of the milk. Currently the breast milk bank preparation and utilisation guidelines have been modified, and these are different across different countries. Some of these reasons were economic, but there were also religious and cultural factors. ${ }^{33}$ The milk bank is used mainly for preterm, orphaned and newborn infants delivered from HIV-positive mothers. Human breast milk is collected, screened, boiled, packed and distributed to the customers based on the strict guidelines developed by the breast milk bank or ministry of health of the country. ${ }^{34,35}$

Criteria to donate breast milk: Before donation of the milk the mother must be sure that she has adequate amounts of breast milk. This means that she has adequate production of milk beyond the needs of her infant. The time of donation is preferably during the first three months of postnatal period. In addition, a study shows that in order to give or donate breast milk to the bank the mother should have good support and care at home. ${ }^{36}$

If the mother is a candidate for breast milk donation, she must not use any medication, for a short or long period of time, even for recreational activity. The mother should not decide to give/donate breast milk on her own; rather she should communicate with her husband and her physician, as well as the infants' physician. When the mother's willingness to donate breast milk is confirmed, she will be tested or screened for her total healthiness. This test/screen includes history taking, physical examination, blood test and urine analysis, and other tests will be done in order to prevent disease to be transmitted through breast milk. Then the mother should be instructed on how to express her milk. The expression may be done manually or by a pump which is given from the milk bank. Then the mother will put the expressed milk in the freezer until the milk is 


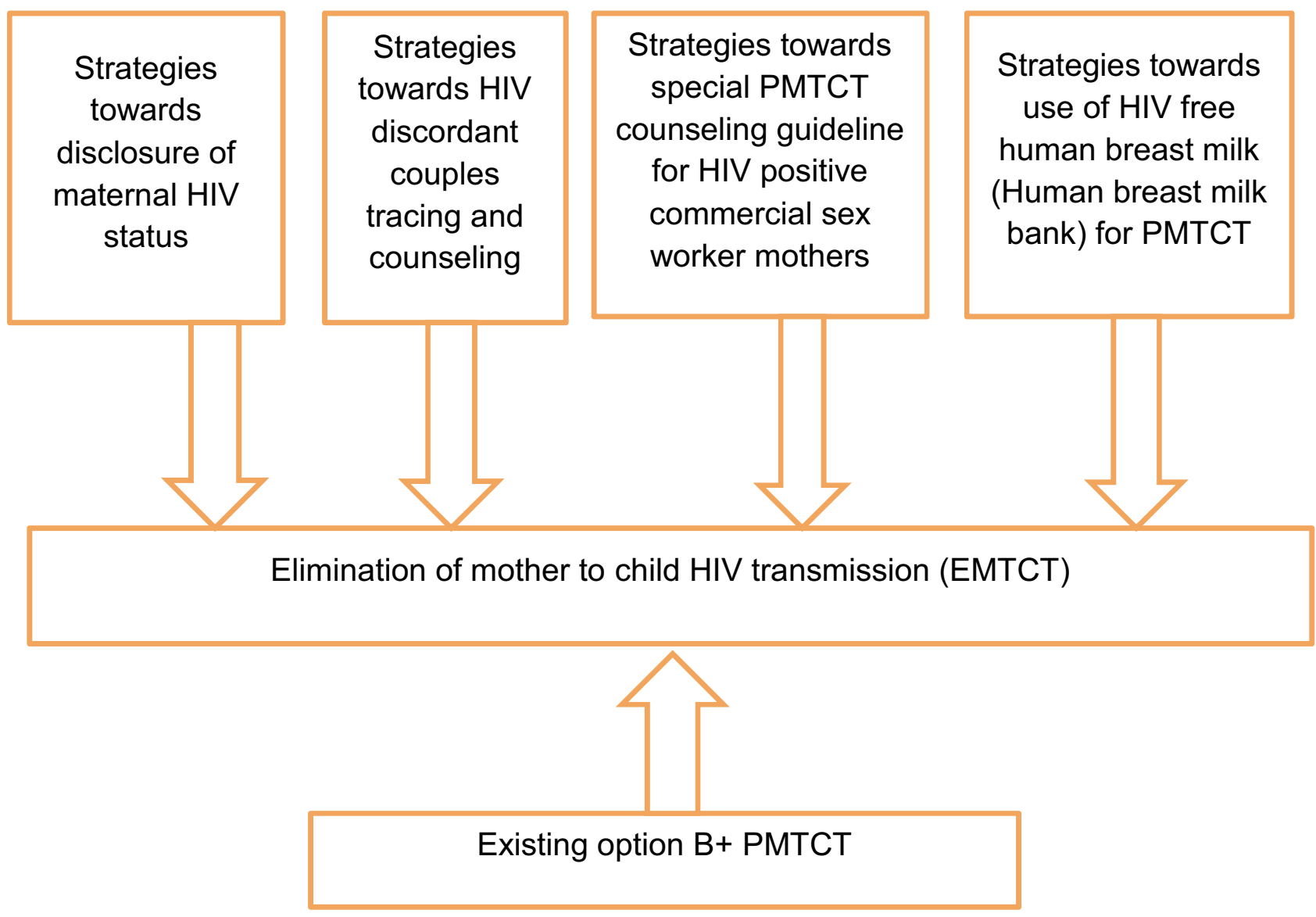

Figure I Framework of key areas for strategy development to eliminate MTCT of HIV in Addis Ababa governmental hospitals, Ethiopia, 2018.

taken by the milk bank or other responsible milk collector. The transportation system must be always in a cold chain or cold box. Breast milk donation is an act of cheerfulness. ${ }^{36,37}$

Processing at the human milk bank: Human breast milk will pass through different steps before it is used for infants feeding. The most common type of steps followed by different milk banks are the following. ${ }^{38,39}$

Screening: Eligible milk donors can be screened with a short interview, giving informed consent and a sample of blood for screening. Donation site: milk donor mothers can give the expressed milk at the milk bank or in a local collection centre. Donated milk record/ registration: Raw milk is checked into the computer database, and each deposit is labelled with a unique code. This can identify the milk all the way from the logging room to the recipient. Boiling: Pasteurisation of the milk is conducted with strict use of clean techniques during preparation and processing. The pasteurisation staff should monitor the milk as it slowly thaws. Once thawed, the milk is poured into flasks. Evaluation: Before mixing, donated milk will be analysed for its nutritional value so that each bottle of milk can be labelled with the caloric and protein content before being dispensed to a customer. Packaging: The pasteurised milk is packed in $100 \mathrm{~mL}$ or $200 \mathrm{~mL}$ bottles, and each is labelled with its nutritional information. A batch number, expiration date and unique code which are matched to hospital logs and tracking systems will be created. Pasteurising: Once bottled, the milk is gently pasteurised at $62.5^{\circ} \mathrm{C}$ for 30 minutes. This holder method of pasteurisation can kill potentially harmful viruses and bacteria but does not harm the majority of the milk's immunological properties and beneficial components. The nutritional composition of the milk remains constant. Freezing: After the process is completed bacterial culture will be done to be sure that there are no harmful bacteria in the donated milk. Pasteurised milk is frozen and stored at $-20^{\circ} \mathrm{C}$ until it is distributed to the customer. Delivery: when the milk is requested by 
Table 3 Strategies to Establish and Use Human Breast Milk Bank for PMTCT in Addis Ababa Governmental Hospitals, Ethiopia, 2018

\begin{tabular}{|l|l|}
\hline Strategy & $\begin{array}{l}\text { Rationale and } \\
\text { Operationalisation }\end{array}$ \\
\hline $\begin{array}{l}\text { Use of banked human breast milk } \\
\text { for PMTCT }\end{array}$ & $\begin{array}{l}\text { To have HIV-free breast milk for } \\
\text { HIV-exposed infants. }\end{array}$ \\
hstablishment and expansion of & $\begin{array}{l}\text { Since the programme is new for } \\
\text { the country, awareness creation } \\
\text { Ethiopia }\end{array}$ \\
Increase the awareness of \\
community about the use of \\
human breast milk bank & $\begin{array}{l}\text { To introduce the importance of } \\
\text { human breast milk bank as } \\
\text { Include use of banked human } \\
\text { breast milk for EMTCT with } \\
\text { option B+ }\end{array}$ \\
$\begin{array}{l}\text { Training for HIV-positive } \\
\text { mothers and health professionals } \\
\text { about human breast milk bank as } \\
\text { alternative choice of feeding for } \\
\text { PMTCT }\end{array}$ & \\
\hline
\end{tabular}

the customer, the milk will be packed thoroughly and will be transported under cold box conditions.

Taking into consideration the key findings of this study, the researcher developed strategies on the following issues. Table 3 sets out strategies on how to establish and use the human breast milk bank for PMTCT (Table 3).

\section{Strategy Towards Discordant Couples Tracing and Counselling Guidelines for PMTCT}

Couples testing together were better for mutual disclosure, change of attitude and behaviour regarding prevention of HIV and improvement in reproductive health compared to couples testing individually. This type of approach (couple testing) is important even for sexual partners who are HIV-negative (sero-concordant couples). The World Health Organization recommends that antenatal care service is the right place for couple HIV testing and counselling to take place. ${ }^{13,40}$ This couple testing together is also important to each sexual partner to understand the HIV status of their partner easily. This makes disclosure simple and more appropriate because the disclosure is immediately after the test, and there will be less tension for the health professional who gives the service.

Taking into consideration the key findings of the study, the researcher forwards the following strategy

Table 4 Strategy Towards Development of Discordant Couples Tracing and Counselling Guideline for PMTCT in Addis Ababa Governmental Hospitals, Ethiopia, 2018

\begin{tabular}{|c|c|}
\hline Strategy & Rationale and Operationalisation \\
\hline $\begin{array}{l}\text { Obligatory couple counselling and testing guideline } \\
\text { preparation }\end{array}$ & $\begin{array}{l}\text { When mothers come for ANC for the first time, they should come with their partner, so that } \\
\text { they will know their HIV status together. } \\
\text { This will help to have a communication between the couples about use of condom during } \\
\text { sexual intercourse, planning of appropriate time for pregnancy, use of ART and proper } \\
\text { PMTCT. Couples testing together and sharing their result can support each other, to access } \\
\text { and adhere to ART and interventions to prevent MTCT. }\end{array}$ \\
\hline $\begin{array}{l}\text { Promotion about couple HIV testing and } \\
\text { counselling (CHTC) }\end{array}$ & $\begin{array}{l}\text { CHTC should be promoted by health policy-makers, programme planners and health } \\
\text { providers so that it is possible to increase the community awareness about the advantage of } \\
\text { couple HIV testing and counselling. } \\
\text { At the community level, the existing health service about CHTC should be active (encourage } \\
\text { community participation and include community leaders and religious leaders regarding the } \\
\text { importance of couple testing and counselling for HIV). Promotion of CHTC needs creative } \\
\text { thinking according to the community religion, culture and norm. }\end{array}$ \\
\hline $\begin{array}{l}\text { Couple HIV testing and counselling to reduce } \\
\text { mother-to-child HIV transmission }\end{array}$ & $\begin{array}{l}\text { CHTC should be considered as the best strategy to reduce/eliminate MTCT of HIV because it } \\
\text { increases the adherence to PMTCT and creates good communication within couples. In this } \\
\text { case the couple can discuss difficult issues because of the good environment created by the } \\
\text { counsellor. HIV transmission prevention, treatment of the infected partner if they are } \\
\text { discordant and care decisions can be settled together, and communication about } \\
\text { contraceptives, use of condom and becoming pregnant can be made together with the } \\
\text { recommendation of the counsellor. }\end{array}$ \\
\hline
\end{tabular}


about discordant couples with regard to the elimination of mother-to-child HIV transmission (EMTCT). Table 4 sets out the rationale and operationalisation of this strategy (Table 4).

\section{Strategy Towards Disclosure Guidelines for PMTCT}

Disclosure is considered to be when one of the sexual partners tells his/her HIV status to the other or when couples communicate with each other about their HIV status. Knowing one's HIV result alone (without sexual partner) will result in fear of telling or disclosing to his/ her sexual partner. In such cases they need a special assistance from a counsellor or health professional. Even this is true only if the partner wants to have a consultation. Therefore couple HIV testing and counselling (CHTC) confirm immediate disclosure for the couples. When couples know their HIV status together, the necessary agreements and decisions can be made without any difficulty. ${ }^{41}$
Trained health professionals take the responsibility and follow appropriate ethical procedures to notify patients' sexual partner of HIV status. This happens in the following scenarios. $^{42}$ The HIV-positive partner has been thoroughly counselled and agreed; Counselling of the HIVpositive person had been unable to effect the necessary attitude changes; The HIV-infected partner has refused to disclose and the HIV-positive person has been given adequate information about why partner notification is required.

By considering the key findings of the study, the researcher forwards the following strategies and rationalisation about disclosure of HIV status with regard to the elimination of mother-to-child HIV transmission (EMTCT) as set out in Table 5.

\section{Strategy Towards Development of Special PMTCT Guidelines for HIV-Positive Commercial Sex Worker Mothers}

Commercial sex worker mothers are the vulnerable group of people for HIV infection and transmission to

Table 5 Strategy Towards Developing Disclosure and Counselling Guideline for PMTCT in Addis Ababa Governmental Hospitals, Ethiopia, 2018

\begin{tabular}{|c|c|}
\hline Strategy & Rationale and Operationalisation \\
\hline Mutual disclosure of HIV status for couples & $\begin{array}{l}\text { When sexual partners or couples conduct their HIV testing mutually } \\
\text { and know their HIV status together, this is considered as couple } \\
\text { counselling and disclosure. This kind of service had many advantages for } \\
\text { the couples. It can help to settle and have follow-up by ART clinic, link } \\
\text { to their local or nearest health institution for the sustainable follow-up } \\
\text { service and it is also important to use these couples as model } \\
\text { counsellors and educators in the community regarding the importance } \\
\text { of couple counselling and testing together. } \\
\text { This couple testing together is also important to each sexual partner to } \\
\text { understand the HIV status of their partner easily, and it makes } \\
\text { disclosure simpler and more appropriate because the disclosure is } \\
\text { immediately after the test, resulting in less tension for the health } \\
\text { professional who provides the service. }\end{array}$ \\
\hline $\begin{array}{l}\text { Disclosure of their own HIV status for } \\
\text { children } \\
\text { The best way for a child to learn about their HIV status is through age- } \\
\text { appropriate information shared by a loving, trusted and responsible } \\
\text { caretaker }\end{array}$ & $\begin{array}{l}\text { Disclosure to children should never happen informally, unintentionally } \\
\text { during anger or conflict. } \\
\text { A child's maturity and cognitive capacity varies and is not only } \\
\text { dependent on age. } \\
\text { It is important to discuss HIV status while considering the child's } \\
\text { intellectual level and the child's individual situation. } \\
\text { Assessments of family readiness for disclosure and potential barriers to } \\
\text { disclose are important. } \\
\text { The benefits of disclosure on both short- and long-term consequences } \\
\text { on the family and child should be considered. } \\
\text { Children aged more than } 12 \text { years should know their HIV status. }\end{array}$ \\
\hline
\end{tabular}


Table 6 Strategy Towards the Development of Special PMTCT Guidelines for HIV-Positive Commercial Sex Worker Mothers in Addis Ababa Governmental Hospitals, Ethiopia, 2018

\begin{tabular}{|c|c|}
\hline Strategy & Rationale and Operationalisation \\
\hline $\begin{array}{l}\text { Special PMTCT service for HIV-positive } \\
\text { commercial sex worker mothers }\end{array}$ & $\begin{array}{l}\text { Existing option B+ PMTCT programme lacks adequate coverage for pregnant female sex } \\
\text { workers. } \\
\text { PMTCT service for female sex workers like tracing, counselling and retention system must be } \\
\text { strict and separated from others. } \\
\text { Considering financial support and social protection mechanism for poor FSWs' families must be } \\
\text { included to overcome financial crisis. } \\
\text { Antenatal care, labour and delivery, and postpartum services should be delivered in a user- } \\
\text { friendly environment for female sex worker women living with HIV. }\end{array}$ \\
\hline $\begin{array}{l}\text { Prevent stigma and discrimination for HIV- } \\
\text { positive sex worker mothers }\end{array}$ & $\begin{array}{l}\text { To increase use of PMTCT service by sex worker mothers } \\
\text { Enhancing participatory education for the community to reduce HIV stigma and discrimination } \\
\text { which should be undertaken by non-governmental organisations and community-based } \\
\text { organisations; and conducting a study addressing health facility issues focusing on PMTCT } \\
\text { services for female commercial sex workers. }\end{array}$ \\
\hline
\end{tabular}

other people. Prevention of HIV transmission from mother to child is very difficult among the sex worker mothers. ${ }^{43}$ Understanding the factors that pose barriers for access to PMTCT by these vulnerable groups will contribute valuable information that will aid in developing strategies and policies towards targets of PMTCT access. Pregnancy without having a husband encounters discrimination by neighbours and the community. In developing countries home delivery among sex workers were $52.7 \%$. One key factor making them keep away from public health facilities is the discrimination they face from the community. Being a FSW and being HIV-positive caused the FSWs to face the double burden of discrimination in the community as well as at health facilities. ${ }^{44}$ Taking into consideration the key findings of the study, the researcher forwards the following strategies and operationalisation about PMTCT in commercial sex workers mothers as set out in Table 6.

\section{Conclusion and Recommendations Conclusion}

This study used qualitative approach to evaluate the effect of option B+ PMTCT in Addis Ababa and to develop alternative strategies that contribute to eliminate MTCT. The study explored issues that increase MTCT; these were: HIV serodiscordant couples, HIV-positive commercial sex worker mothers, absence of HIV-free breast-milk for PMTCT and lack of disclosure of HIV status for sexual partner.

\section{Recommendation}

The researcher forwarded the following four recommendations for Ethiopian Ministry of Health and other non-governmental responsible bodies in Ethiopia. The recommendations are: establish and use banked human breast milk for elimination of MTCT together with option B+ PMTCT; incorporate obligatory policy for discordant couple testing, counselling and disclosure with option B+ PMTCT; develop disclosure policy and counselling guideline for PMTCT; formulate special PMTCT guideline for HIV-positive commercial sex worker mothers. Future research should assess the acceptability and challenges of the above strategies.

\section{Ethical Approval and Informed Consent}

This research was approved by the University of South Africa (UNISA), department of health study with IRB number (Approval REC-012714-029(NHERC) Number: HSHDC/ 589/2017). Official permission was obtained from the relevant authorities at each study hospital with letter number: AAHB $5720 / 227$. The ethical approach in this study is according to the Declaration of Helsinki. Participants over the age of 18 years were informed about the aim of the study, benefit and risks of participating in the study as well as their rights and responsibilities. Volunteers participating in the study signed the informed consent form. To ensure participant confidentiality and anonymity, identification numbers were added to interview audio recordings, questionnaires and transcription records. Linkages of participants' personal information and the study identification numbers remained confidential. The study 
identification number list was kept on the researcher's computer and locked in a password-protected folder. The data from the patients' and health professionals' demographic questionnaire were kept anonymous and confidential, and results were aggregated to ensure that participants' responses cannot be linked to them. The participants were not identifiable through the study identification numbers.

To ensure confidentiality, the electronic versions of the transcripts and digital audio files were stored on a password-protected external hard drive and computer, with access limited to the researcher. All data should be deleted from the computer and hard drive five years after completion of the study. Hard copies of the data from all study participants were kept in a locked cabinet in the researcher's room and should be destroyed two years after the study is completed.

\section{Acknowledgments}

The authors want to forward our deepest thanks to the following individuals for their unreserved and committed contributions to this research thesis: UNISA's Professors, UNISA-Ethiopia regional learning center staff and consultants who assisted us starting from proposal writing to the end of this study; and Addis Ababa city administration health bureau ethical committee for reviewing our application and granting us permission to conduct this study.

\section{Disclosure}

The authors have declared that there is no conflict of interest for this study.

\section{References}

1. UNAIDS. Global Epidemic of HIV 2019; 2019.

2. Burusie A. Determinants of Mother to Child HIV Transmission (HIV MTCT); a case control study in Assela, Adama and Bishoftu Hospitals, Oromia Regional State, Ethiopia. Cell Dev. 2015;4: 1000152. doi:10.4172/2168-9296.1000152

3. Ethiopian Public Health Institute, Ethiopian Public Health Association, Centers for Disease Control and Prevention. Ethiopian National Key Population HIV Sero-behavioral surveillance (NHSBS) Round Progress Report. Addis Ababa: Ethiopian Ministry Health. 2014.

4. Berhan Z, Abebe F, Gedefaw M, Tesfa M. Prevalence of HIV and associated factors among infants born to HIV positive women in Amhara Region, Ethiopia. Int J Clin Med. 2014;5:464-474.

5. WHO and UNICEF. HIV Transmission Through Breastfeeding: A Review of Available Evidence. World Health Organization: Geneva; 2014.

6. Lewis P. Cell-free human immunodeficiency virus type 1 in breast milk. J Infect Dis. 2014;177(1):34-39.

7. World Health Organization. Scaling up HIV services for women and children: towards elimination mother-to-child transmission and improving maternal and child health in the context of HIV. Towards universal access: scaling up priority HIV/AIDS interventions in the health sector. Gene. 2013.
8. WHO. WHO HIV Prevention and Treatment Guidelines. Antiretroviral Drugs for Treating Pregnant Women and Preventing HIV Infection in Infants, Towards Universal Access: Recommendations for a Public Health Approach. Geneva: World Health Organization; 2016.

9. WHO. The elimination of mother-to-child transmission of HIV Conceptual framework for the Middle East and North Africa Region Towards the elimination of mother-to-child transmission of HIV. 2015a.

10. Ethopian federal ministry of health. National Guidelines for Comprehensive HIV Prevention, Care and Treatment; 2017.

11. UNICEF. Celebrating the Innocenti Declaration on the Protection, Promotion and Support of Breastfeeding: Past Achievements, Present Challenges and the Way Forward for Infant and Young Child Feeding. FLorence: Innocenti Research Centre; 2015.

12. EMOH. Ethiopia Country/Regional Operational Plan Towards PMTCT, Strategic Direction Summary; 2017.

13. WHO. World Health Report 2015 Make Every Mother and Child Count. Geneva: World Health Organization; 2015b.

14. WHO Collaborative Study Team. Effect of breastfeeding on infant and child mortality due to infectious diseases in less developed countries: a pooled analysis. WHO Collaborative Study Team on the role of breastfeeding on the prevention of infant mortality. Lancet. 2013;368(9202):451-455.

15. WHO. 2016. Consolidated Guidelines on the Use of Antiretroviral Drugs for Treating and Preventing HIV Infection. Recommendations for a Public Health Approach. 2nd ed. Geneva. Http://www.who.int/ hiv/pub/arv/arv-2016/en/.

16. FHAPCO. HIV/AIDS Anual Report in Ethiopia. 2014:4-5

17. UNAIDS. Global Plan Towards the Elimination of New HIV Infection Among Children and Keeping Their Mothers Alive from 2011 to $2015 ; 2014$.

18. Creswell JW. Research Design: Qualitative, Quantitative, and Mixed Methods Approaches/John W. 4th ed. Creswell; 2014.

19. Ethiopian federal ministry of health. National guidelines for prevention of mother to child HIV transmission. Addis Ababa, Ethiopia; 2015.

20. Tadesse. Assessment of HIV discordance and associated risk factors among couples receiving HIV test in Dilla, Ethiopia. BMC Res Notes. 2014;7:893.

21. Stirratt J, Remien R, Smith A. The role of HIV serostatus disclosure in antiretroviral medication adherence. AIDS Behav. 2011;10(5):483.

22. Kadowa I. Factors influencing disclosure of HIV positive status in Mityana district of Uganda. Afr Health Sci. 2014;9(1):26-33.

23. Negesse D, Addis K, Awoke A, Birhanu Z, Muluye D. HIV positive status disclosure and associated factors among children in North Gondar, Northwest Ethiopia. Int Scholarly Res Net AIDS. 2012; 2012:1-7.

24. Alencar LC, Seidl EM. Breast milk donation: women's donor experience. Revista De SaúdePública. 2015;43(1):70.

25. Chung J, Leung Y, Yau SY. Perceptions of breastfeeding mothers on breast milk donation and establishment of human breast milk bank in Hong Kong: a qualitative study. Int J Nurs. 2015.

26. Jean-Charles Picaud Neonatology, Hopital de la croix rousse, L. (France). French human milk banks association, European milk banks association (EMBA). INAC Milk Banking Worldwide. 2017.

27. Tully M, Jones F. Donor Milk Banking in Riordan, Breastfeeding and Human Lactation. 2013:471.

28. Hartmann BT, Pang WW, Keil AD, Hartmann PE. Best practice guidelines for the operation of a donor human milk bank in an Australian NICU. Early Hum Dev. 2013;83(10):66.

29. Thomaz A, Loureirom L, Oliveira T, et al. The human milk donation experience: motives, influencing factors, and regular donation. $J$ Human Lactation. 2015;24(1):69-76.

30. Bertino E, Giuliani F, Occhi L, Coscia A, Tonetto P. Benefits of donor human milk for preterm infants: current evidence. Early Hum Dev. 2016;85:S9-S10. 
31. Willis B, Welch K. Health of female sex workers and their children: a call for action. Lancet Glob Health. 2016;4(7):e438.

32. Stahlman S, Hargreaves JR, Sprague L, Stangl AL. Measuring sexual behavior stigma to inform effective HIV prevention and treatment programs for key populations. JMIR Public Health Survei. 2017;3(2)

33. Arslanoglu S. ESPGHAN Committee on Nutrition: donor human milk for preterm infants: current evidence and esearch directions. $J$ Pediatr Gastroenterol Nutr. 2013;57:535-554.

34. Medicine T. ABM Clinical Protocol \#10: breastfeeding the late preterm infant (34 0/7 to 36 6/7 weeks gestation) (first revision June 2011). Breastfeed Med. 2011.

35. Arnold L. Human Milk in the NICU: Policy into Practice. Ontario: Jones and Bartlett Publishers; 2010.

36. HMBANA. Human Milk Banking Guidelines for the Establishment and Operation of a Donor Human Milk Bank; 2015.

37. Yigit D, Sayik D. Wet-nurse and breast milk bank. J Pat Care. 2018;4:138. doi:10.4172/2573-4598.1000138

38. Czank C, Simmer K. Simultaneous pasteurization and homogenization of human milk by combining heat and ultrasound: effect on milk quality. J Dairy Res. 2012;77:183.
39. Moro G. Heat treatment of human milk. $J$ Pediatr Gastroenterol Nutr. 2015;54:165.

40. Chemaitelly. Distinct HIV discordancy patterns by epidemic size in stable sexual partnerships in sub- Saharan Africa. Sex Transm Infect. 2012;88:51-57.

41. Becker. Comparing couples' and individual voluntary counseling and testing for HIV at antenatal clinics in Tanzania: a randomized trial. AIDS Behav. 2010;14:558-566.

42. Kaiser. Factors associated with HIV infection in married or cohabitating couples in Kenya: results from a nationally representative study. PLoS One. 2011;6(3):e1784.

43. Hhealth MM 2015. Myanmar National Strategic Plan and Operational Plan on HIV and AIDS 2011 - 2015. Available from: http://www.ilo.org/wcmsp5/groups/public/—ed_protect/—protrav/— ilo_aids/documents/legaldocument/wcms_174886.pdf.

44. Burnet. Barriers to Access to PMTCT Services by Female Sex Workers National AIDS Program and UNICEF Myanmar Research Conducted by Burnet Institute Myanmar. 2014:17

\section{Publish your work in this journal}

HIV/AIDS - Research and Palliative Care is an international, peerreviewed open-access journal focusing on advances in research in HIV, its clinical progression and management options including antiviral treatment, palliative care and public healthcare policies to control viral spread. The manuscript management system is completely online and includes a very quick and fair peer-review system, which is all easy to use. Visit http://www.dovepress.com/testimonials.php to read real quotes from published authors. 